\title{
Mathematical model for the power generation from arbitrarily oriented photovoltaic panel
}

\author{
Qusay Hassan ${ }^{1,3}$, Marek Jaszczur ${ }^{1, *}$, Estera Przenzak ${ }^{2}$ \\ ${ }^{1}$ Department of Fundamental Research in Energy Engineering, Faculty of Energy and Fuels, AGH \\ University of Science and Technology, Poland \\ ${ }^{2}$ Department of Sustainable Energy Development, Faculty of Energy and Fuels, AGH University of \\ Science and Technology, Poland \\ ${ }^{3}$ Department of Mechanical Engineering, University of Diyala, Iraq
}

\begin{abstract}
In this paper, a mathematical model for modelling the solar radiation components and photovoltaic arrays power outputs from arbitrarily oriented photovoltaic panel has been presented. Base on the model electrical power prediction of the photovoltaic system in realistic local condition has been presented and compared with experimental measurement. The results show the effectiveness of the proposed model, which provides tools to better understand the performance and reliability as well as decision-making tool in designing of a hybrid renewable energy base power generation system. It has been shown that base on the model prediction, the efficiency and possible failures of the system can be found which are important from the technical and economical point of view.
\end{abstract}

\section{Introduction}

Among of the renewable energy sources, solar energy is one of the most alternative and sustainable energy resources in the world. It's ubiquitous, safe, plentiful, available for free, and environmentally friendly [1-3]. The key drawback of solar systems is unpredictable nature and in consequences the unpredictable system power output. The electrical energy production depends on the local weather and climatic conditions [4-6]. Despite the great progress in weather forecast still accurately solar radiation prediction it is not possible. Additionally, due to still relatively low solar energy to electrical energy conversion [3], the research and development efforts should be made to optimize the overall system performance of the solar systems and create new ways to predict the exact production from the environmental and climatic conditions available [7]. This is particularly important for the hybrid energy system design and analysis. Selected site data of the solar radiation are the best source of information for the proper design and investigation of solar energy conversion systems assessment [8]. In the literature [2, 13, 14] a large number of models have been proposed in order to calculate energy production from solar radiation and they can be used for a variety of purposes in the design and development of solar power systems. But most of the models has based on the daily, monthly or yearly averaged statistical data and it is not able to estimate instantaneous power production. From production-

\footnotetext{
*Corresponding author: jaszczur@agh.edu.pl
} 
consumption point of view, instantaneous power production and not averaged are highly desirable and key in complex system analysis of hybrid systems which utilities wind turbines, heat pumps, fuel cells and energy storage.

The designing and evolution of solar power systems depend primarily on the solar radiation data in particular on the total solar radiation solar radiation incident on (normal component) the PV module surface. But the most of the weather stations measure intensities of total (diffusive and global) solar radiation on the horizontal surfaces [9]. This generates significant difficulty in the direct utilization of measured data to evaluate the incident solar irradiation on an arbitrarily oriented photovoltaic panel. Incoming radiation on tilted surface is the sum of the sunbeam radiation, the three components of diffuse radiation and the radiation reflected from the various surrounding surfaces for example ground. In order to reconstruct direct beam and diffuse solar radiation components from the global horizontal irradiation (measurement) mathematical models have been used $[10,11]$.

In the presented paper, a mathematical model for modelling the solar radiation components as well as electrical power outputs from arbitrarily oriented photovoltaic panel has been shown. Base on the realistic local condition the electrical power prediction of the PV system has been presented and compared with the experimental measurement from Faculty test system.

\section{Theory and models}

The weather data (solar radiation, air temperature) and PV system instantaneous power were acquired from the weather meters (Pyranometers \& Thermometer) and solar panels located at AGH University of Science and Technology campus, building D4. The global solar radiation and air temperature data were taken for the year 2015, from $1^{\text {st }}$ January to $31^{\text {st }}$ December with the sampling 5 minutes. The PV model and solar model was used for the determination of the power generation from the photovoltaic panel for the location 50.066354N, 19.918191E, Krakow, Poland. In Fig.1a the local monthly average ambient temperature $\mathrm{T}_{\text {air }}$ base on the measurement and in Fig. $1 \mathrm{~b}$ the monthly average daily solar radiation together with clearness index are presented. The PV power output directly depends on the amount of radiation incident the surface of the PV array and array temperature.
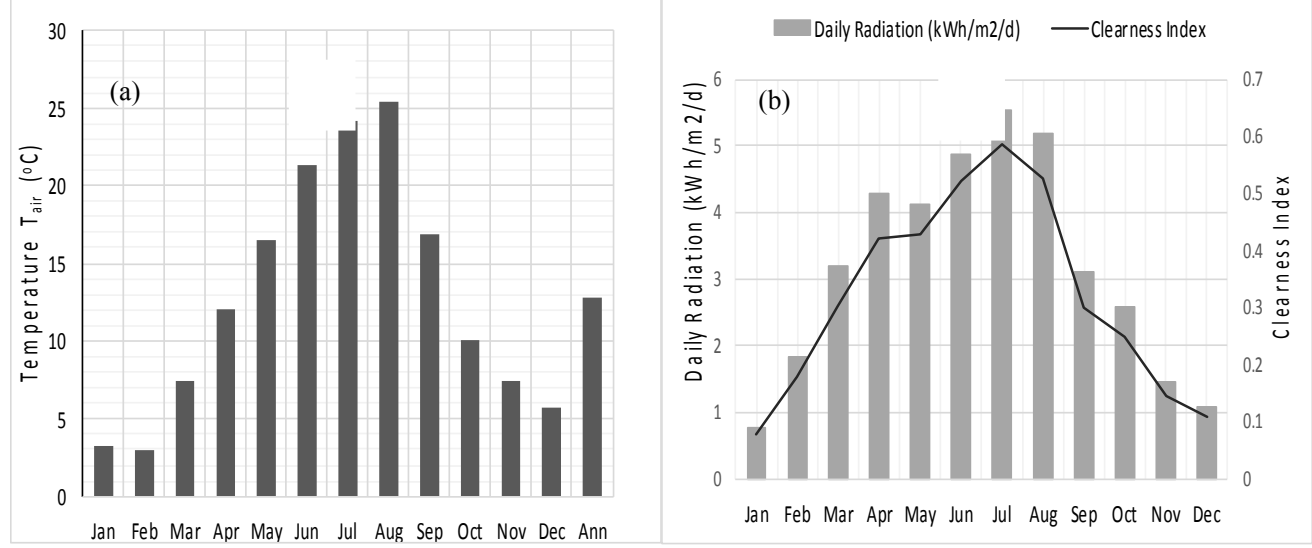

Fig. 1. (a) The ambient temperature $T_{a i r}$ and (b) the total solar radiation/clearness index.

The global solar radiation incident on the arbitrary oriented the PV array surface was calculated using Hay and Davies, Klucher and Reindl (HDKR) Model [16]. 


\subsection{Determination solar radiation components}

In general, the time of the day affects the location of the sun in the sky, which we can describe by an hour angle $\omega$ (in degree). This value is equal zero at solar noon, negative and positive before and after solar noon respectively and can be calculated as follows [13].

$$
\omega=(t s-12 h r) \cdot 15^{\circ} / h r
$$

where $t_{S}$ is the solar time calculates from the civil time as:

$$
t_{s}=t_{c}+\frac{\lambda}{15^{\circ} / h r}-Z_{c}+E
$$

where $t_{C}$ is the civil time in hours corresponding to the midpoint of the time step, $\lambda$ is the longitude $\left[^{\circ}\right], Z_{C}$ is the time zone in hours east of GMT and $E$ is the equation of time.

The equation of time $E$ accounts for the effects of obliquity and the eccentricity of the earth's orbit, and can be calculated as follows [13]:

$$
E=3.82\left(\begin{array}{c}
0.000075+0.001868 \cos B-0.032077 \sin B \\
-0.014615 \cos 2 B-0.04089 \sin 2 B
\end{array}\right)
$$

where $B$ is calculated using the day of the year $n$ :

$$
B=360 \frac{(n-1)}{365.2425}
$$

\subsection{Determination of Extraterrestrial Solar Radiation on Horizontal Surfaces}

The extraterrestrial normal solar radiation $G_{O n}$ is a function of the distance between the earth and the sun and is given as $[12,13,19]$ :

$$
G_{\text {On }}=G_{S C}\left(1+0.033412 \cos \frac{360 n}{365}\right)
$$

where $G_{S C}$ is the solar constant $1.367\left(\mathrm{~kW} / \mathrm{m}^{2}\right)$.

The extraterrestrial horizontal radiation $G_{O}\left(\mathrm{~kW} / \mathrm{m}^{2}\right)$ incident on the horizontal surface at the outer layers of the atmosphere is equal:

$$
G_{O}=G_{\text {on }} \cos \theta_{z}
$$

where $\theta_{z}\left[^{\circ}\right]$ is the zenith angle, value between a vertical line and the line to the sun and this value is zero when the sun is directly overhead, and $90^{\circ}$ when the sun is on the horizon which is expressed as:

$$
\cos \theta_{z}=\cos \phi \cos \delta \cos \omega+\sin \phi \sin \delta
$$

where $\phi\left[^{\circ}\right]$ is the latitude and $\delta\left[^{\circ}\right]$ is the solar declination position of the solar noon with respect to the plane of the equator, can be calculated using the formula proposed by Cooper [14] as follows:

$$
\delta=23.45^{\circ} \sin \left(360^{\circ} \frac{284+n}{365}\right)
$$

The model designed to compute each value every time step so by integrating equation (5) over one time step the average extraterrestrial horizontal radiation $\bar{G}_{O}\left(\mathrm{~kW} / \mathrm{m}^{2}\right)$ over the time step [13] expressed as: 


$$
\bar{G}_{O}=\frac{12}{\pi} G_{\text {On }}\left[\cos \phi \cos \delta\left(\sin \omega_{2}-\sin \omega_{1}\right)+\frac{\pi\left(\omega_{2}-\omega_{1}\right)}{180^{\circ}} \sin \phi \sin \delta\right]
$$

the period between hour angles $\omega_{1}$ and $\omega_{2}$ which define an hour (where $\omega_{2}$ is the larger)

\subsection{Determination the Diffuse Radiation}

The solar radiation coming from the sun is attenuated by the atmosphere and the clouds before it is reaching the surface of the Earth. The ratio of global horizontal radiation entering the Earth's surface to the extraterrestrial horizontal radiation has been defined as:

$$
k_{T}=\frac{\bar{G}}{\overline{G_{O}}}
$$

where $\bar{G}$ is the global radiation on the earth's surface averaged over the time step.

The global horizontal radiation incident on the earth's surface consists two main parts, beam radiation (direct radiation) $\bar{G} b$ and diffuse radiation $\bar{G} d$. The diffusive radiation component comes almost from all the directions and does not cast a shadow. It consists up to three components (isotropic, circumsolar and horizon brightening). The sum of the beam and diffuse radiation is called global solar radiation $\bar{G}$ which is expressed as:

$$
\bar{G}=\bar{G} b+\bar{G} d
$$

The surface orientation has a high effect on the beam radiation (it comes directly from the sun direction) than it does on the diffuse radiation (comes from many directions, on some models is even the direction independent). In the most of the cases the only global horizontal (total) solar radiation and not it's direct and diffuse components. The diffusive radiation component can be evaluated $\bar{G} d$ calculated using the clearness index $k_{T}[15]$ :

$$
\frac{\bar{G}_{d}}{\bar{G}}=\left\{\begin{array}{lc}
1.0-0.09 k_{T} & \text { for } k_{T} \leq 0.22 \\
0.9511-0.1604 k_{T}+4.388 k_{T}^{2}-16.638 k_{T}^{3}+12.336 k_{T}^{4} & \text { for } 0.22<k_{T} \leq 0.80 \\
0.165 & \text { for } k_{T} \leq 0.80
\end{array}\right.
$$

When the sky is clear and the sun is at the highest position on the sky the direct radiation is about $85 \%$ and diffuse radiation is about $15 \%$ (when neglecting reflections) while the percent of diffuse radiation keeps going up to $40 \%$ when the sun is $10^{\circ}$ above the horizon [16].

\subsection{Determination of Incident Solar Radiation on PV array}

The total radiation received by the PV module surface consists of a direct radiation, diffuse radiation and reflected radiation. The diffused radiation is a combination of three components (isotropic, circumsolar and horizon brightening) and the reflected radiation is the radiation reflected from the surrounding ground or any other surfaces if exists. For this reason, different models had been proposed in the literature for estimating the total solar radiation incident the PV module surfaces.

One of the models has been proposed by Hay and Davies, Klucher and Reindl (HDKR model) [16]. This model takes into consideration all key radiation components and the incident total solar radiation $\bar{G}_{T}$ can be calculated from the following formula: 


$$
\bar{G}_{T}=\left(\bar{G} b+\bar{G}_{d} A_{i}\right) R_{b}+\bar{G}_{d}\left(1-A_{i}\right)\left(\frac{1+\cos \beta}{2}\right)\left[1+f \sin ^{3}\left(\frac{\beta}{2}\right)\right]+\bar{G} \rho\left(\frac{1-\cos \beta}{2}\right)
$$

where $\beta$ is the slope of the PV module, $\rho$ is the ground reflectance, which is also called the albedo, $f$ is the horizon brightening factor, $A_{i}$ is the anisotropy index and $R_{b}$ is the ratio of beam radiation on the tilted surface to beam radiation on the horizontal surface all calculated as follows:

$$
f=\sqrt{\frac{\bar{G} b}{\bar{G}}} \quad, \quad A_{i}=\frac{\bar{G} b}{\bar{G}_{o}} \quad, \quad R_{b}=\frac{\cos \theta}{\cos \theta_{z}}
$$

The incidence angle $\theta$ is, the angle between the direction of direct beam radiation and the normal to that surface, and it is given by:

$$
\begin{aligned}
\cos \theta= & \sin \delta \sin \phi \cos \beta-\sin \delta \cos \phi \sin \beta \cos \gamma \\
& +\cos \delta \cos \phi \cos \beta \cos \omega+\cos \delta \sin \phi \sin \beta \cos \gamma \cos \omega \\
& +\cos \delta \sin \beta \sin \gamma \sin \omega
\end{aligned}
$$

where $\gamma$ is the surface azimuth angle defined as the skew of the projection on a horizontal plane of the normal to the surface from the local meridian, with zero due south, east negative, and west positive [18].

\subsection{Determination of PV array power}

The PV module generating electrical power depends on the total solar radiation $\bar{G}_{T}$ incident on the PV surface, which in the most cases is not horizontal but inclined in order to have higher energy production, better condition for module cooling. In order to predict the PV generating power in each computational time step the model must also calculate the global solar radiation incident on the surface of the PV module every time step $[13,15,19]$.

The PV module generating power $P_{P V}$ can be calculated according to the following equation:

$$
P_{P V}=Y_{P V} f_{P V}\left(\frac{\bar{G}_{T}}{\bar{G}_{T, S T C}}\right)
$$

where $Y_{P V}$ is the rated capacity of the PV module (power output under STC conditions), $f_{P V}$ is the PV derating factor introduced taking into account additional factors affecting PV (soiling, losses, shading, snow cover) and the $\bar{G}_{T, S T C}$ is the incident radiation at standard test conditions.

When the information about PV module temperature is known, it is possible to take into account PV efficiency variation due to thermal effects, in that case, the PV module generating power $P_{P V}$ can be calculated as follows:

$$
P_{P V}=Y_{P V} f_{P V}\left[1+\alpha_{P}\left(T_{c}-T_{c, S T C}\right)\right]\left(\frac{\bar{G}_{T}}{\bar{G}_{T, S T C}}\right)
$$


Where $\alpha_{P}$ is the PV temperature coefficient for the power $\left(\% /{ }^{\circ} \mathrm{C}\right), T_{C}$ is the PV module instantaneous temperature and $T_{C, S T C}$ is the PV module temperature $\left({ }^{\circ} \mathrm{C}\right)$ at STC conditions. Standard Test Conditions (STC) properties (solar radiation of $1 \mathrm{~kW} / \mathrm{m}^{2}$, PV cell temperature of $25^{\circ} \mathrm{C}$, and no wind).

\section{Experimental and numerical results}

Mathematical model eq. (1)-(16) have been used to calculate energy production from PV modules. The polycrystalline silicon, monocrystalline silicon and thin film amorphous silicon PV modules of the size $1000 \mathrm{~W}$ and the specifications shown in Table 1. where considered PV derating factor $85 \%$, ground reflection $0 \%$ or $25 \%$ and azimuth angle $\gamma=0^{\circ}$ and three different angles $\beta$ were used $\left(0^{\circ}, 25^{\circ}, 45^{\circ}\right)$ and the angles $\gamma, \beta$ which follow the sun beam direction (i.e. two-directional tracking systems method was implemented). For the cases where the module temperature was taken into consideration, the cell temperature was calculated base on the air temperature and the solar radiation using the energy balance proposed by Antonio et al. [13].

Table 1. PV modules specifications [13].

\begin{tabular}{|l|c|c|}
\hline PV type & $\begin{array}{l}\text { Average value of } \\
\text { efficiency at STC }[\%]\end{array}$ & $\begin{array}{l}\text { Temperature } \\
\text { coefficient of power } \\
{\left[\% /{ }^{\circ} \mathbf{C}\right]}\end{array}$ \\
\hline Polycrystalline silicon & 13.0 & -0.48 \\
\hline Monocrystalline silicon & 13.5 & -0.46 \\
\hline Thin film amorphous silicon & 5.5 & -0.20 \\
\hline
\end{tabular}

The Fig. 2 and 3 show the PV power generating (for $1 \mathrm{~kW} \mathrm{PV}$ array) for a different angle $\beta$ and for the tracking system. Results are presented without module temperature consideration and with module temperature taken into account (results denoted by _T).

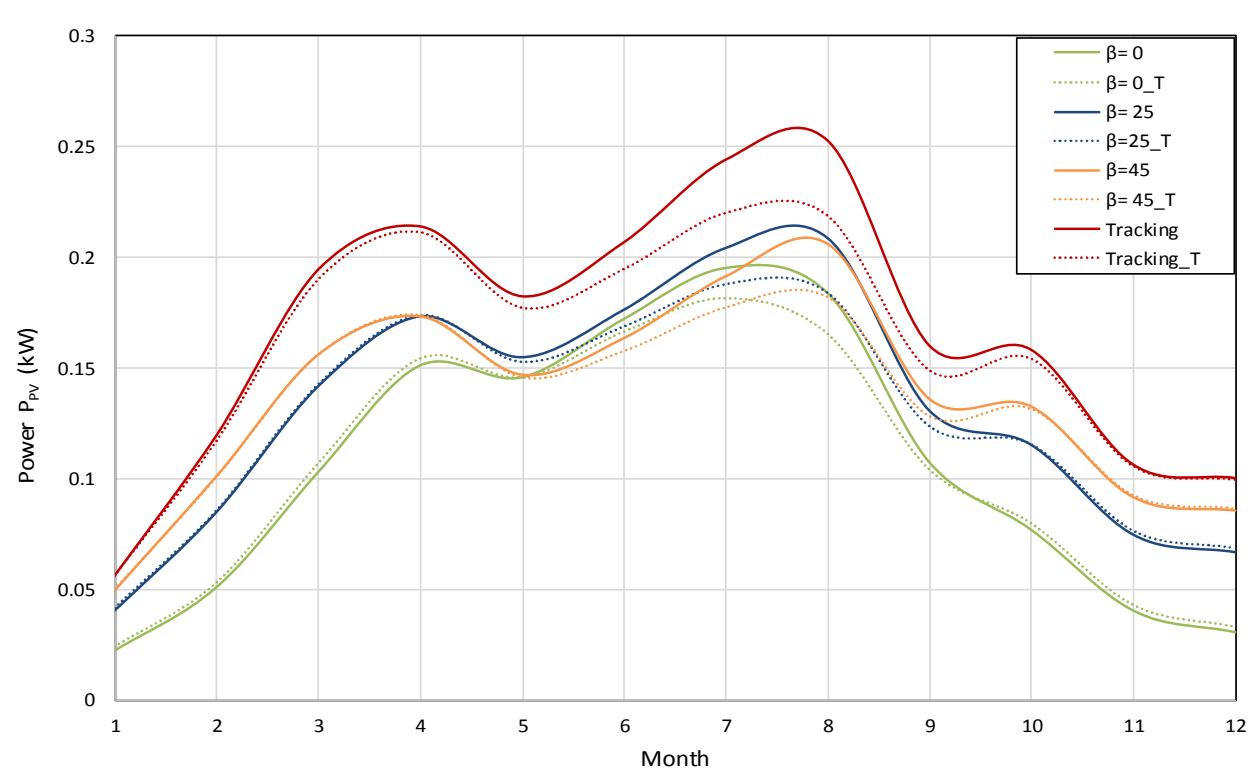

Fig. 2. The monthly average of $\mathrm{PV}$ power generation $P_{P V}$ for Polycrystalline silicon. 


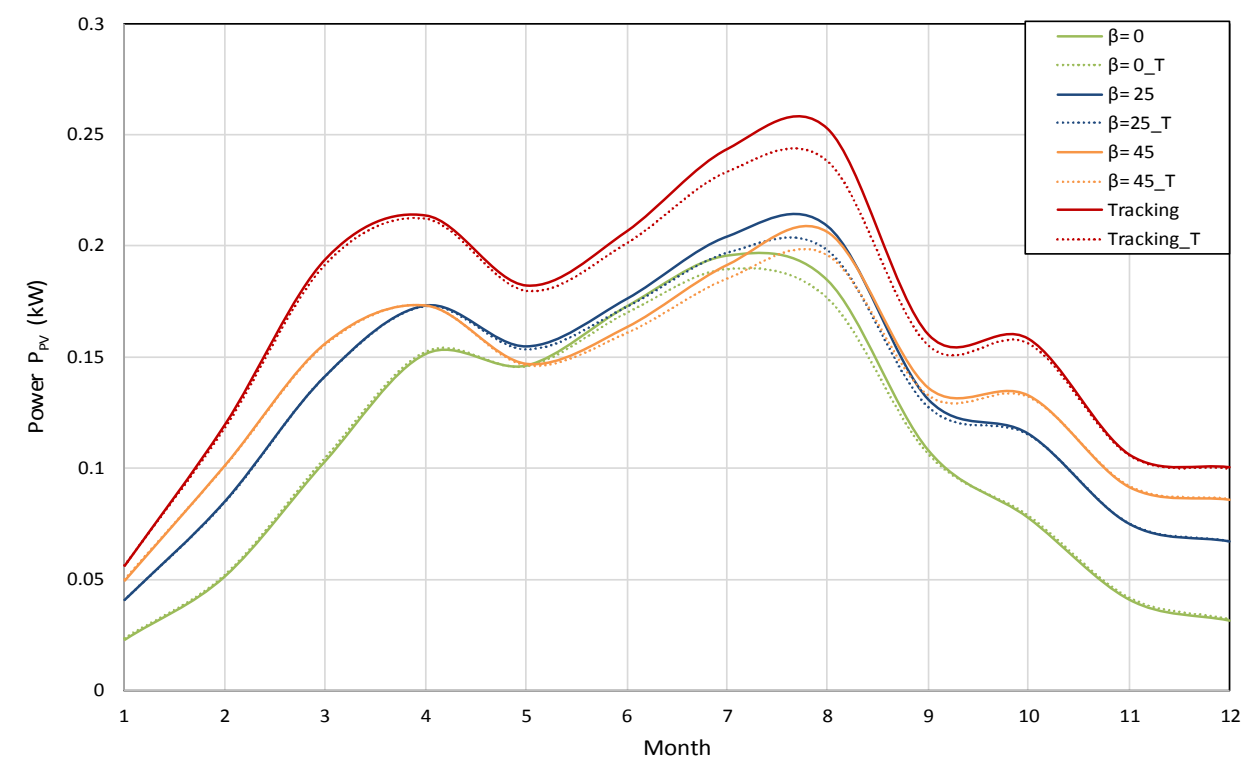

Fig. 3. The monthly average of PV power generation $P_{P V}$ for thin-film amorphous silicon.

It can be seen from Fig. 2 and, 3 that the maximum power generation is for the modules with the tracking system and its degrees by decreasing module slope angle. The total temperature effect is not large and in general it cause power decreasing during the summer and power increasing for other seasons. The results from Fig. 2 and 3 and also for the Monocrystalline silicon are summarized in Table 2 where the annual PV energy production $E_{P V}$ is presented. Modules type temperature affect the annual electrical energy generation and the difference in energy production is about $5 \%$. When the tracking system is used energy production for all PV types is about $60 \%$ higher in reference to the case $\beta=0^{\circ}$.

Table 2. Annual energy production in $(\mathrm{kWh} / \mathrm{yr})$.

\begin{tabular}{|l|c|c|c|c|c|c|c|c|}
\hline \multirow{2}{*}{ PV type } & \multicolumn{2}{|c|}{$\beta=0^{\circ}$} & \multicolumn{2}{c|}{$\beta=25^{\circ}$} & \multicolumn{2}{c|}{$\beta=45^{\circ}$} & \multicolumn{2}{c|}{ Tracking } \\
\cline { 2 - 9 } & $\begin{array}{c}T_{c} \text { non } \\
\text { eff. }\end{array}$ & $\begin{array}{l}T_{c} \\
\text { eff. }\end{array}$ & $\begin{array}{l}T_{c} \text { non } \\
\text { eff. }\end{array}$ & $\begin{array}{c}T_{c} \\
\text { eff. }\end{array}$ & $\begin{array}{c}T_{c} \text { non } \\
\text { eff. }\end{array}$ & $\begin{array}{c}T_{c} \\
\text { eff. }\end{array}$ & $\begin{array}{c}T_{c} \text { non } \\
\text { eff. }\end{array}$ & $\begin{array}{c}T_{c} \\
\text { eff. }\end{array}$ \\
\hline $\begin{array}{l}\text { Polycrystalline } \\
\text { silicon }\end{array}$ & 940 & 921 & 1149 & 1115 & 1196 & 1157 & 1459 & 1384 \\
\hline $\begin{array}{l}\text { Monocrystalline } \\
\text { silicon }\end{array}$ & 940 & 922 & 1149 & 1117 & 1196 & 1159 & 1459 & 1388 \\
\hline $\begin{array}{l}\text { Thin film } \\
\text { amorphous } \\
\text { silicon }\end{array}$ & 940 & 930 & 1149 & 1131 & 1196 & 1176 & 1459 & 1432 \\
\hline
\end{tabular}

Fig. 4 illustrate the ground albedo effect on the PV power generation for the case with the module slope angle $\beta=45^{\circ}$ and for Polycrystalline silicon. Three different values for albedo are considered $\rho=0 \%, 20 \%$ and $40 \%$. The PV module temperature effect is also analyzed. It can be seen that increasing ground albedo power generation is also increasing. At the same time for the cases with module temperature consideration, PV power generation is significantly lower than for the summer time and is increasing for other seasons. 


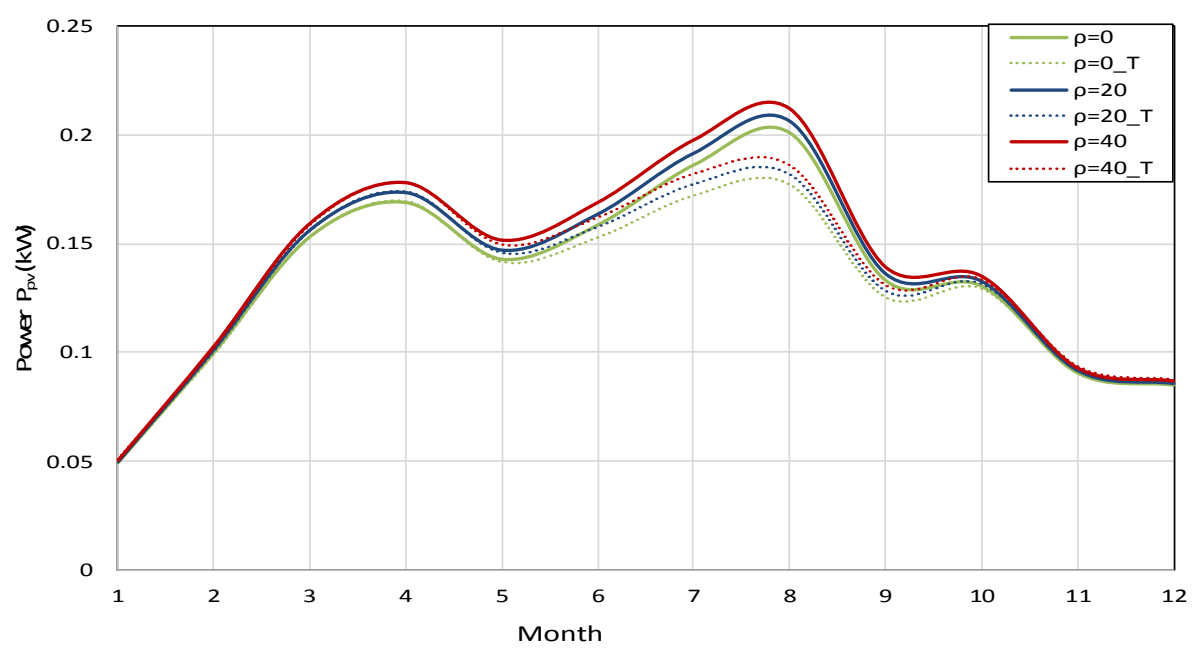

Fig. 4. Albedo of effect on the PV power generation $P_{P V}$ for $\beta=45^{\circ}$ for Polycrystalline silicon.

\section{Model experimental set-up}

In this section, the results from the experimental set-up are compared with the model prediction in order to evaluate system efficiency. The PV system was located on the building D4, AGH University of Science and Technology and is shown in Fig 5(left). The system size was $1.62 \mathrm{~kW}$ (12 panels $\mathrm{x} 135 \mathrm{~W})$ the panels were located with the slope angle $\beta=7.5^{\circ}$ from the horizontal plane and azimuth degree $\gamma=20^{\circ}$ west. The cells have been made from thin-film amorphous a-Si/ $\mu \mathrm{c}-\mathrm{Si}$ (Sharp model NA-E135L5), the temperature coefficient of power was $-0,24 \% /{ }^{\circ} \mathrm{C}$, the nominal operation temperature NOCT $46^{\circ} \mathrm{C}$ with efficiency $9.6 \%$ at STC. The PV modules were connected to the $1.61 \mathrm{~kW}$ converter working with the efficiency $94.2 \%$. It was assumed for the simulations that, the albedo value is $25 \%$ and derating factor $85 \%$ (which include energy losses of $5 \%$ and $10 \%$ for the panel surface pollution). Fig. 5 (left) shows the array composed of polycrystalline silicon type modules.
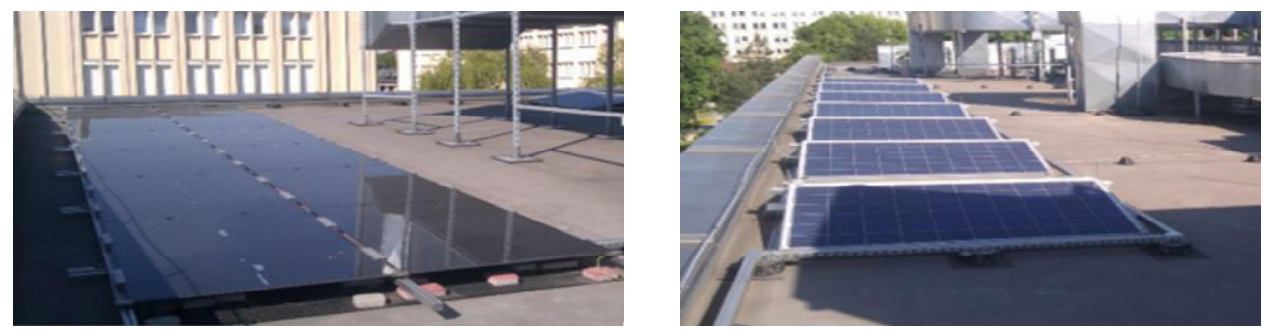

Fig. 5. PV modules located on the roof of D4 building, AGH University of Science and Technology: (left) thin film amorphous silicon type and (right) polycrystalline silicon type.

From the Fig. 5 it can be seen shadowing as well as additional reflection from the ventilation devices located on the roof. This may significantly influence the PV system. In Fig. 6a experimental results obtained from measurement are compared with the numerical prediction for two different days (at winter and summer). On the $30^{\text {th }}$ of July 2015 at morning and afternoon hours due to shadow effect power production is much smaller that 
model prediction. At winter time when solar radiation is lower and additionally due to a large number of cloudy days, the solar radiation diffusive component is dominated the difference is smaller. But in general, for most of the time, real power production is much lower than theoretical prediction. The difference is caused by significant system shadowing and the modules overheating.
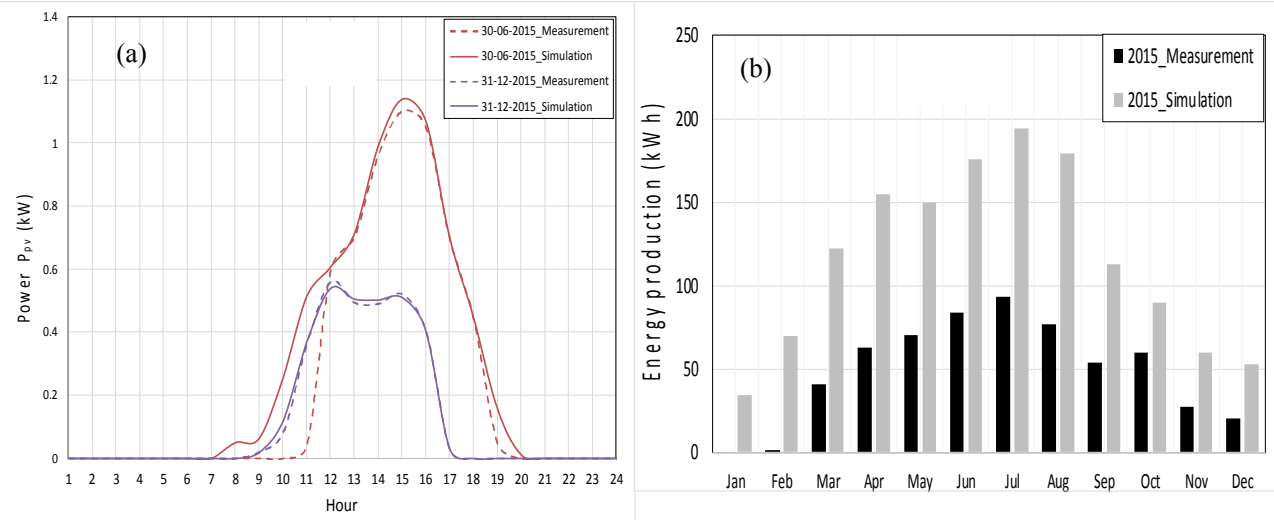

Fig. 6. (a) The PV modules power generation: experimental measurement vs model prediction, (b) The energy generation $E_{P V}$ by the PV system: for the test system and for model prediction.

In the Fig. $6 \mathrm{~b}$ the monthly energy production obtained from the measurement has been compared with the model prediction for the whole year 2015. It can be seen that system generate much lower electrical energy than was obtained from the computer simulations. The total energy production predicted with the presented model was $E_{P V}=1371 \mathrm{kWh}$ which agree well with theoretical prediction for Poland (for $1.61 \mathrm{~kW} P_{P V \max }$ modules up to $1610 \mathrm{kWh}$ electrical energy should be produced), while according to experimental measurement only $589 \mathrm{kWh}$ was produced. This shows that the system efficiency is about $57 \%$ of the nominal conditions. This also shows that only about $3 \%$ of the primary solar energy is converted to the electrical energy.

\section{Conclusions}

In the present paper mathematical model for photovoltaic modules power estimation together with the model for total solar radiation decomposition have been presented. Presented model can be used for the electrical energy production calculation and provides tools to better understanding the performance of the systems and can be considered as a decision-making tool in designing of a hybrid renewable energy base on solar energy. In the present work three different most popular PV module types have been analyzed. It has been showing that the modules angle, as well as PV module temperature or ground albedo, may influence the system instantaneous power generation. Results show that tracking system may increase energy generation about $60 \%$. Ground reflectance has also a significant effect on the energy production, particularly when the slope angle $\beta$ is relatively high.

It has been detected that PV experimental set-up has very high losses due to shadow effective from ventilation devices (for example almost no energy production during January and February). The total electrical energy production for 2015 estimated using proposed model and local solar radiation measurement is $1371 \mathrm{kWh}$ while the real energy production obtained from the measurement is only $589 \mathrm{kWh}$. This shows that the actual system efficiency is about $57 \%$ of nominal conditions and the system performance has to be improved. 
Through these results, we can explain that the actual system lows efficiency due high effect of the shadow and non-optimum slope angle of the panels $\beta=7.5^{\circ}$ and this lead losing solar radiation and increase panel temp during the summer for very low ventilation as well as increase panel surface pollution for non-effect rain angle cleaning.

The present work was supported by the Polish Ministry of Science (Grant AGH No.11.11.210.312).

\section{References}

1. H. Li, W. Ma, Y. Lian and X.Wang, "Estimating daily global solar radiation by day of year in China”. Applied Energy, 87: pp. 3011-3017. (2010)

2. P. Hersch and K. Zweibel, "Basic photovoltaic principles and methods". Antimicrob. Agents Chemother., vol. 58, no. 12, pp. 7250-7, 1982.

3. A.Q. Jakhrani, A.K. Othman, A.R.H. Rigit and S.R. Samo, "A simple method for the estimation of global solar radiation from sunshine hours and other meteorological parameters" IEEE ICSET 2010, pp. 6-9, (2010)

4. P. Nema, R.K. Nema and S. Rangnekar, "A current and future state of art development of hybrid energy system using wind and PV-solar: A review" Renewable and Sustainable Energy Reviews, 13(8): pp. 2096-2103, (2009)

5. E.M. Nfah, J.M. Ngundam and R. Tchinda, "Modeling of solar/diesel/battery hybrid power systems for far-north Cameroon”, Renewable Energy, 32: pp. 832-844, (2007)

6. M. T. Y. Tadros, "Uses of sunshine duration to estimate the global solar radiation over eight meteorological stations in Egypt," Renewable Energy, 21 (2), pp. 231-246, (2000)

7. M.K. Deshmukh, S.S. Deshmukh, "Modeling of hybrid renewable energy systems" Renewable and Sustainable Energy Reviews, 12(1): pp. 235-249, (2008)

8. A.A. Sabziparvar, "A simple formula for estimating global solar radiation in central arid deserts of Iran”. Renewable Energy, 33: pp. 1002-1010 (2008)

9. E.G. Evseev and A.I. Kudish, "The assessment of different models to predict the global solar radiation on a surface tilted to the south" ,Solar Energy, 83: pp. 377-388, (2009)

10. K. Soga, H. Akasaka and H. Nimiya, "A comparison of methods to estimate hourly total irradiation on tilted surfaces from hourly global irradiation on a horizontal surface”, Kagoshima University, 1-4-7, Korimoto, Kagoshima, 890-0065, (1999)

11. A.Q. Jakhrani, A.K. Othman, A.R.H. Rigit, S.R. Samo and S.A. Kamboh, "A novel analytical model for optimal sizing of standalone photovoltaic systems" Energy, 46, pp. 675-682, (2012)

12. J. Duffie, W. Beckman "Solar Engineering of Thermal Processes" $4^{\text {th }}$ edition, Wiley, New York, NY, (1991)

13. H. Antonio, S. Hegedus, "Handbook of photovoltaic science and engineering", (2003)

14. D. Erbs, S. Klein, J. Duffie ,"Estimation of the diffuse radiation fraction for hourly, daily, and monthly-average global radiation", Solar Energy,(1982)

15. N. Mahammad, Encyclopaedia of Geomorphology, pp. 66, (2006)

16. K. N. Shukla, S. Rangnekar, and K. Sudhakar, "Comparative study of isotropic and anisotropic sky models to estimate solar radiation incident on tilted surface: A case study for Bhopal, India”, Energy Reports, 1, pp. 96-103, (2015)

17. B. Liu, R. Jordan, "The long term average performance of flat plate solar energy collectors", Solar Energy, 7, pp. 53-7, (1963)

18. VA. Graham, KGT. Hollands "A method to generate synthetic hourly solar radiation globally”, Solar Energy, 44 (6), pp. 333-341, (1990)

19. C. D. Whiteman and K. J. Allwine, "Extraterrestrial solar radiation on inclined surfaces",1, 3 (1986) 